\title{
Analysis and Optimation Hydrofoil Supported Catamaran (HYSUCAT) Size 25 Meter Based on CFD Method
}

\author{
Hari Prastowo ${ }^{1}$, Agoes Santoso ${ }^{2}$, Andre Arya B ${ }^{3}$
}

\begin{abstract}
However, the ship still has constraints on speed and fuel consumption. Therefore, the ship has many variations of shape to achieve optimal condition. For example the body of ships with double hulls (catamaran) or three (trimaran), that using foil to make ship can have a smaller resistance to achieve optimal efficiency. The purpose of this research in order to plan the maximum foil shape which can produce high force of buoyance on the catamaran boat ( 25 meters) and also to determine the type of hydrofoil that produces maximum buoyance force using CFD method.
\end{abstract}

Keywords - optimal, foil, buoyance force, CFD, chord, profile.

\section{INTRODUCTION}

$\mathrm{H}$ ydrofoil Supported Catamaran (Hysucat) is one ship with a hybrid type, which is combines a hydrofoil type boats with catamaran type vessel. She uses the motor as a power producer in the propulsion system. This type of ship is expected to have a higher efficient than the fast boat or catamaran type with deep-v mono-hull vessel [1].

She uses the principle of such an aircraft, using foil or wing as a produce of buoyance force. This force is intended to lift the hull that will give the damping effect that can reduces the wet surface area of the ship, so it can reduce the ship resistance, so when power of prime mover is same, the ship will be able to drive at higher speeds which automatically increases efficiency of the ship [2].

The foil should be located on keel it size is not to be less than the breadth of the vessel and must be placed at the LCG (length of center of gravity) to produce balance of force lift and produces desired of trim. At the beginning of this type of vessel, Hysucat used one of foil on the LCG ship, so that use of foil with a variation of pitch is really needed. The use of foil with variable pitch is extremely difficult, because of sea wave conditions always changed. To cope with it, tail foil is used, which foil with smaller dimensions then the main foil which serve to adjust the trim on the part after the vessel as desired. By using this tail foil, the use of variable pitch foil is not needed [3].

This research is designed to optimize main foil and tail foil toward produce of lift force to the ship with a 25meter catamaran type. Therefore, by using foil on this Hysucat can generate lift force and achieve maximum efficiency.

Hari Prastowo is with Department of Marine Engineering, Institut Teknologi Sepuluh Nopember, Surabaya 60111, Indonesia. E-mail: hprastowo@its.ac.id

Agoes Santoso is with Department of Marine Engineering, Institut Teknologi Sepuluh Nopember, Surabaya 60111, Indonesia. E-mail: agoes@its.ac.id

Andre Arya B is with Department of Marine Engineering, Institut Teknologi Sepuluh Nopember, Surabaya 60111, Indonesia.
Objective for design a foil shape which fits on a catamaran boat is to plan the maximum foil shape as a producer of lift force and can determine which type of hydrofoil is produces the maximum lift force on 25 meter catamaran type boats.

\section{METHOD}

In terms of mono-hull and multi-hull, this is the basic type number of hulls. With the general design of monohull ship is type of vessel that has a single hull ship. However in time by time, with purpose to achieve a better efficiency, including speed, resistance and balance, then occur the ships with multi-hull types, which number of hull is more than one; two (catamaran), three (trimaran) and five (pentamaran). But in precipitating the design of a multi-hull vessel is also caused by a form of culture, namely the culture of Polynesia in India [4].

\section{A. History and definition of boat type catamaran.}

Definition of the catamaran vessel is a vessel which consists of double hull which each of inter-hull connected with a structure, be it a frame or bridging as the platform of the ship [1-4]. The platform is free from water surface, so that the vessels with larger deck area may have smaller sea water resistant, due to the wet surface area of the ship is smaller than the mono-hull ship types. The height of catamaran's deck platform is suite to the type of the ship and the route. The combination of large deck and low weight of ships makes this type more reliable for cargo transportation service between cities as well as for tourism.

Historically for beginning of multi-hull types catamaran ship is since the Paravas Era, fishing communities on the south coast Tamik Nadu, India, where the Polynesian catamaran and canoes allowed for occupy an uninhabited island and the farthest in the world.

At that moment the sailors mind in the western area who are familiar with this type of mono-hull boats have doubts because of the design of multi-hull vessels are very strange to them which is the balance of the vessel based on the design instead of weight distribution. But the doubt is indisputable because catamaran boats become the best design to kapal feri cepat (fast ferries) 
with speed, balance and capacity of the vessel is awesome.

Type of twin hull sailing boat or motor boat has been available since the cruise ship (pleasure craft), generally because of velocity and balance. Maximum speed of catamaran ferry vessel can reach speeds of 40 knots (74 $\mathrm{km} / \mathrm{h})$. Generally, catamaran length is about 15 feet until 330 feet, and it is including the fastest sailing ships and motor boats.

\section{B. Hull design with multi-hull of catamaran type}

Hull designed of catamaran is dissimilar each vessels. There are many models physique of catamaran. When viewed at a glance by a top sectional, catamaran type vessel consisted of a kind:

1) Symetrical

2) Asymmetric with the inside straight.

3) Asymmetric with the outside straight.

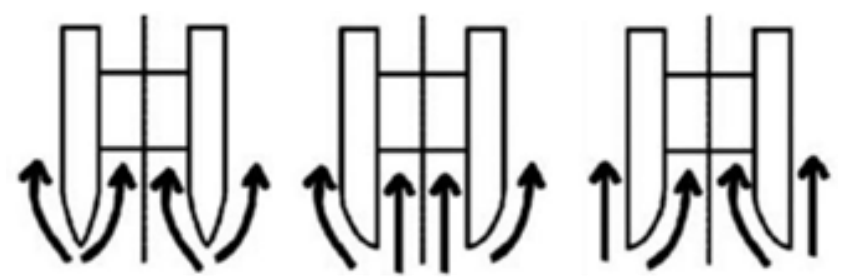

Figure. 1. Hull Shape of catamaran (a) symmetry, (b) asymmetry with the inside straight,(c) asymmetry with the outside straight

\section{Discussing about catamaran}

When discuss about catamaran, is not only talk about one type of hull, but also explained about the many types of hull construction and optimization for different purposes.
In a transverse sectional, shape of hull catamaran can be classified into several types:

1) Basic catamaran.

2) Pontoon or hydroairy type and.

3) SWATH (small waterplan area twin hull).
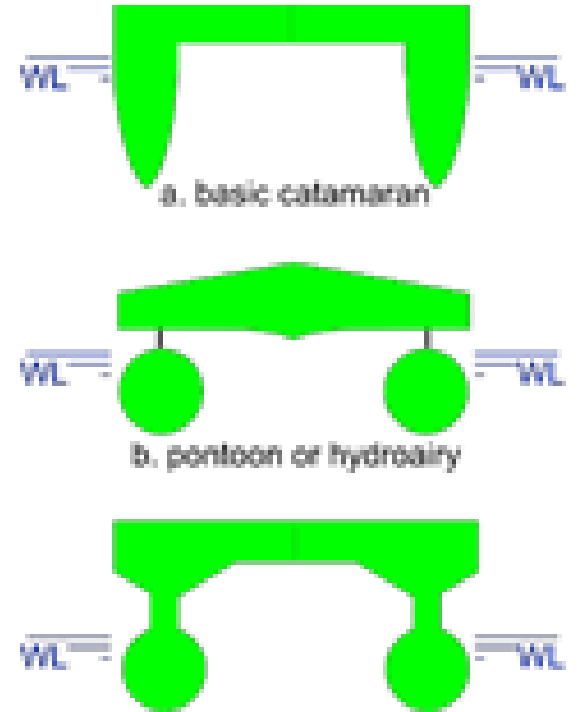

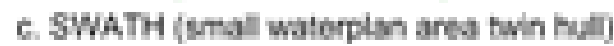

Figure. 2. Hull Shape of catamaran transversely

\section{Definition of Hysucat}

W Ships Hysucat (Hydrofoil Catamaran Support) is a ship with a hybrid type that uses foil as a tool for producing lift force with the aim to minimize the ship resistance. Hysucat is a type of hybrid boats that combine between model of catamaran and foil that was previously used on a monohull hydrofoil type boats.

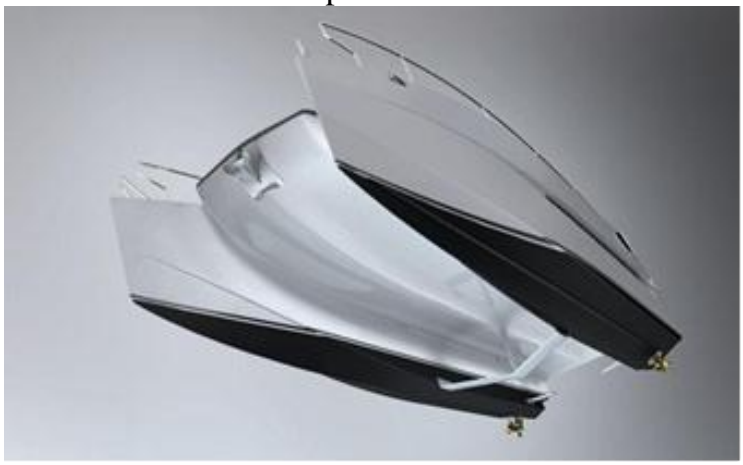

Figure. 3. Hyusucat Ship 


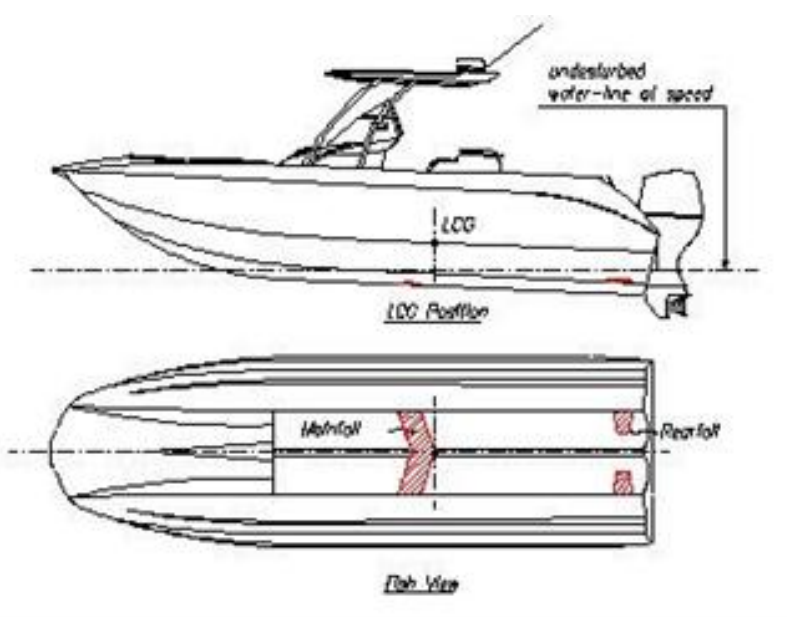

Figure. 4. Foil Hyusucat located

Hydrofoil on this ship has a wing-like structures installed below the water line with have characteristic such as the wings on airplanes. With a streamlined profile characteristics, which create water pressure at the top of the foil is lower than the pressure at the bottom of the foil, causing the lift force on the hull. The sum of all elements related to the lifting force on the foil generate the lift "L" (lift) the vertical direction of the water flow, and "D" (Drag force) which is parallel to the direction of water flow.

In general, the type of hysucat vessel only have one foil, main foil located on LCG (long of center of gravity) so the ship was lifted just in center of gravity. But in this case, it takes foil with a pitch that can be changed to produce lift that is required based on different water conditions, so the use of a single main foil on this type of vessel hysucat still not reached maximum efficiency.

With the addition of tail foil, the rear wing is located at the stern part of the ship, can maintain vessel trim condition in which high speed, thereby increasing its efficiency, the use of the main foil with a pitch that can be set is no longer needed.

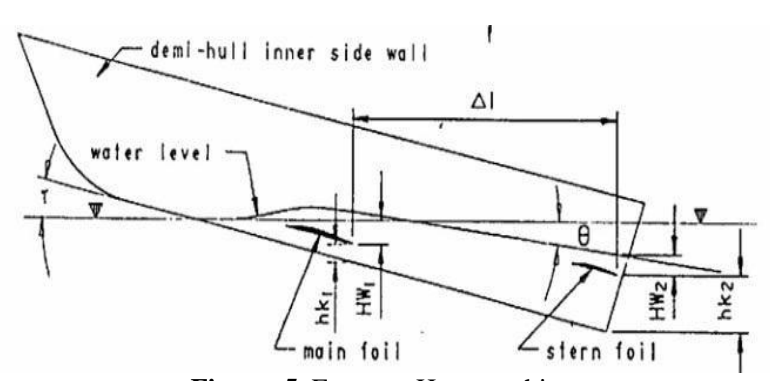

Figure. 5. Force on Hysucat ship

\section{E. Definition of NACA Foil Series}

NACA shape of the foil used for aircraft, developed by the National Advisory Committee for Aeronautics (NACA). The shape of the foil NACA is illustrated/ described by serial digit number after the word "NACA". Parameters in a numeric code can be entered into the calculations to generate cross-sectional shape of the foil and other parts appropriately.

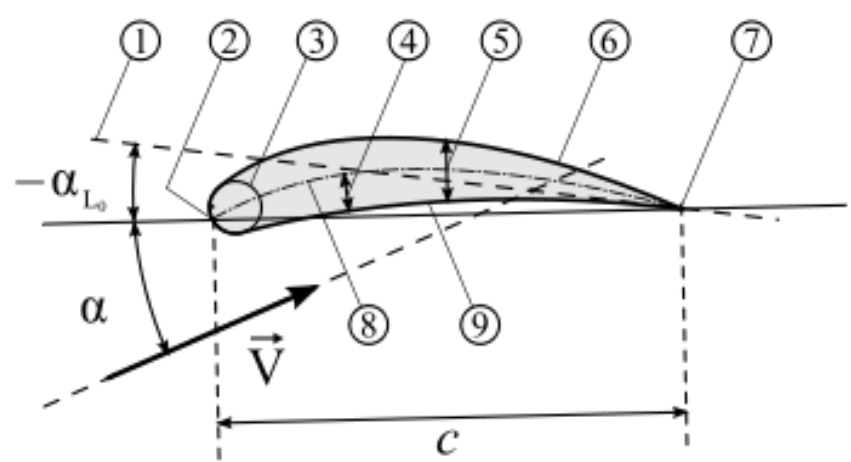

Figure. 6. Profile geometry - 1: Zero lift line; 2: Leading edge;3: Nose circle; 4: Camber; 5: Max. thickness; 6: Upper surface; 7: Trailing edge; 8: Camber mean-line; 9 : Lower 
Cross-sectional shape NACA 4 digit series is determined by the following profiles:

1) The first number describing the percentage taken from the maximum chamber chord

2) The second number describing the maximum distance from the leading -edge chamber foil ( 0 10) which is percent of chord.

3) The last two digits describe the maximum thickness of the foil is taken of the percentage of chord.

\section{F. Cofficient of Lift and Drag of Foil}

The lift coefficient is the coefficient of lift generated by the foil. Drag coefficient is the value of the coefficients generated by the drag foil. In trials comparing many models, this value is used as reference for comparison. This is due to different extents foil on each model of the value of this coefficient which proves how effective style lifts or Drag to the width of foil given

$$
\begin{aligned}
& L=C_{L} \cdot 0.5 \cdot \rho \cdot U_{\infty}^{2} \cdot S \\
& C_{L}=\frac{L}{0.5 \cdot \rho \cdot U_{\infty}^{2} \cdot S}
\end{aligned}
$$

Formula of Drag Coefficient, known as:

$$
\begin{aligned}
& D=C_{D} \cdot 0.5 \cdot \rho \cdot U_{\infty}^{2} \cdot S \\
& C_{D}=\frac{D}{0.5 \cdot \rho \cdot U_{\infty}^{2} \cdot S}
\end{aligned}
$$

Where:

$$
\begin{array}{ll}
C_{L} & =\text { Coefficient of Lift } \\
C_{D} & =\text { Coefficient of Drag } \\
L & =\text { Force Of Lift } \\
D & =\text { Force Of Drag } \\
\rho & =\text { Fluid Density } \\
U & =\text { Velocity of Fluid } \\
S & =\text { Surface Area }
\end{array}
$$

\begin{tabular}{|c|c|c|}
\hline LWL & 26.741 & $\mathrm{~m}$ \\
\hline Beam & 8.918 & $\mathrm{~m}$ \\
\hline Draft & 0.992 & $\mathrm{~m}$ \\
\hline Displaced volume & 68.478 & $\mathrm{~m}^{3}$ \\
\hline Wetted area & 156.677 & $\mathrm{~m}^{2}$ \\
\hline Prismatic coeff. & 0.622 & \\
\hline Waterplane area coeff. & 0.472 & \\
\hline $1 / 2$ angle of entrance & 13.57 & deg. \\
\hline LCG from midships(+ve for'd) & -0.181 & $\mathrm{~m}$ \\
\hline Transom area & 0.049 & $\mathrm{~m}^{2}$ \\
\hline Transom wl beam & 7.457 & $\mathrm{~m}$ \\
\hline Transom draft & 0.025 & $\mathrm{~m}$ \\
\hline Max sectional area| & 4.119 & $\mathrm{~m}^{2}$ \\
\hline Bulb transverse area & 0.009 & $\mathrm{~m}^{2}$ \\
\hline Bulb height from keel & 0 & $\mathrm{~m}$ \\
\hline Draft at FP & 1 & $\mathrm{~m}$ \\
\hline Deadrise at $50 \%$ LWL & 0 & deg. \\
\hline Hard chine or Round bilge & \multicolumn{2}{|c|}{ Hard chine } \\
\hline Frontal Area & 0 & $\mathrm{~m}^{2}$ \\
\hline Headwind & 0 & kts \\
\hline Drag Coefficient & 0 & \\
\hline Air density & 0.001 & tonne $/ \mathrm{m}^{3}$ \\
\hline Appendage Area & 0 & $\mathrm{~m}^{2}$ \\
\hline Nominal App. length & 0 & $\mathrm{~m}$ \\
\hline Appendage Factor & 1 & \\
\hline Correlation allow. & 0.0004 & \\
\hline Kinematic viscosity & $1.19 \mathrm{E}^{-06}$ & $\mathrm{~m}^{2} / \mathrm{s}$ \\
\hline Water Density & 1.026 & tonne $/ \mathrm{m}^{3}$ \\
\hline
\end{tabular}

\section{RESULTS AND DISCUSSION}

\section{A. Modelling}

The modeling is done based on the data of comparative ship. Modeling done by the application maxsurf dongle ver 11:12. Of the models that have been made, obtained the following model specification

TABLE 1 .

SPEC MODEL 3D USING MAXSURF 11.12 

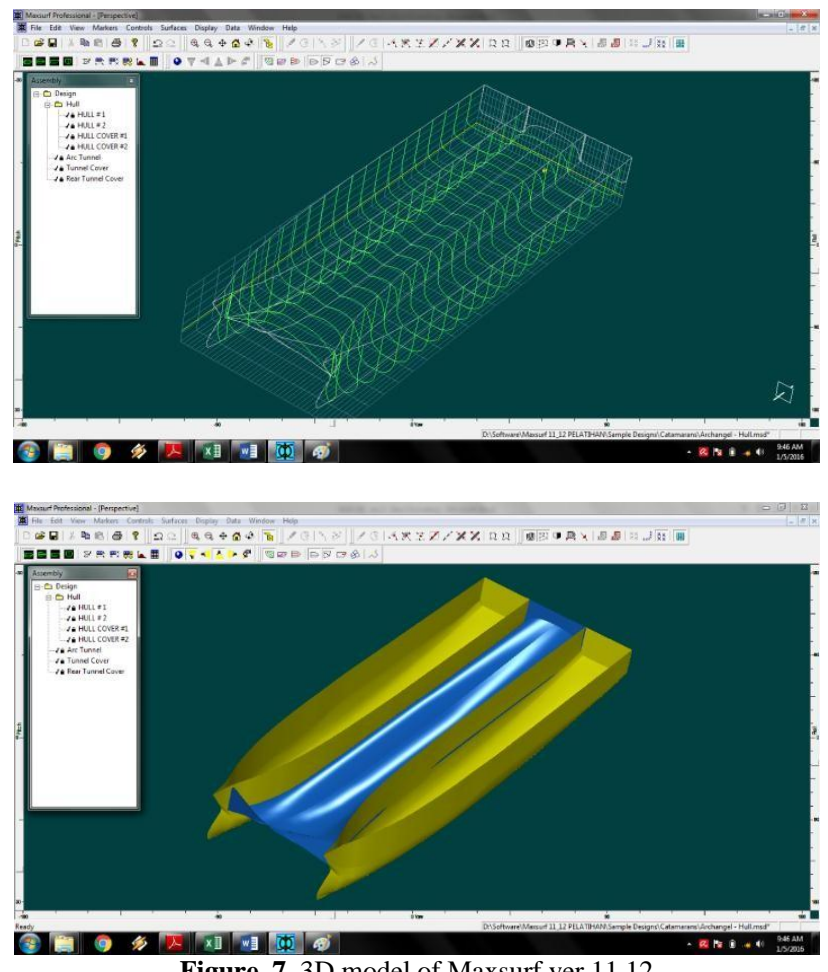

Figure. 7. 3D model of Maxsurf ver 11.12

\section{B. Variations}

Model foil which will be analyzed have some kind of variation, both types of profiles are foil will used or foil chord length.

Foil used is a kind of foil NACA-4 series. According to the coordinates obtained from the web address www.airfoiltools.com, obtained coordinates used to create a section of the foil as a 3D model in the application MAXSURF 11.12.

5 types of foil have different randomized to know foil that has the best efficiency. Foil profile types used are:
1) Foil 2212.
2) Foil 2306.
3) Foil 2309.
4) Foil 4306.
5) Foil 4712.

C. Variations done to foil chord is length, and angle of attack (AOA) of Foil.

Then will be analyzed for the highest efficiency results. For variety foil chord length is $3.0 \mathrm{~m}, 2.5 \mathrm{~m}$, $2.0 \mathrm{~m}, 1.5 \mathrm{~m}, 1.0 \mathrm{~m}$. while for AOA foil ranging from $0^{\circ}$; $4^{\circ} ; 8^{\circ} ; 12^{\circ} ; 16^{\circ} ; 20^{\circ} ; 22^{\circ} ; 24^{\circ} ; 28^{\circ} ; 32^{\circ} ; 35^{\circ}$.

\section{Analysis of Foil Model.}

Analysis from model foil (NACA 4 series) done with some kind of dimensions to determine the lift and drag force contained in the foil in some conditions of AOA (angle of attack). By knowing the lift force on the foil, it can be seen that the foil can move displacement amount of water on the ship, so change the initial detention of the ship.

Foil model analysis conducted by the initial dimensions:

- Span: $3.5068 \mathrm{~m}$

- Chord: $3 \mathrm{~m}$

- Speed: 25 knots

Using applications from 13.0 ANSYS ICEM CFD and CFX is to analyze models of foil made.

So from this analysis obtained the following table.

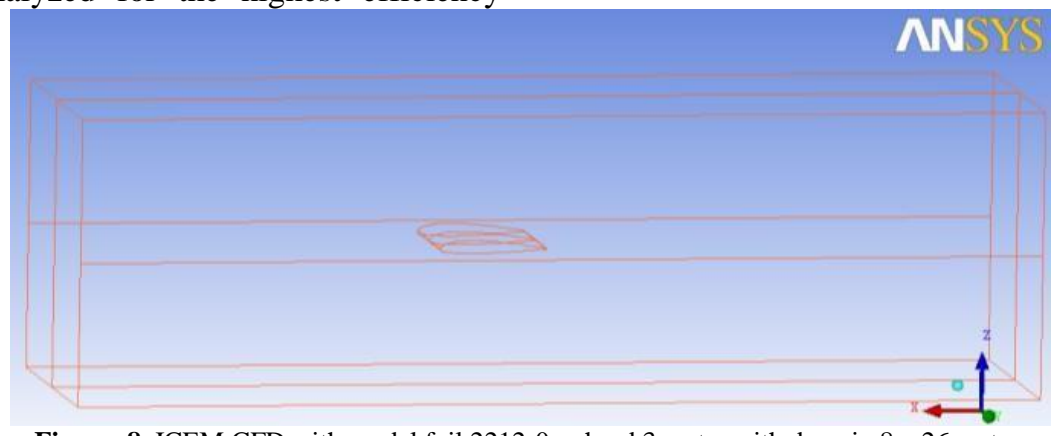

Figure. 8. ICEM CFD with model foil 2212-0o-chord 3 meter with domain 8 x 26 meter. 


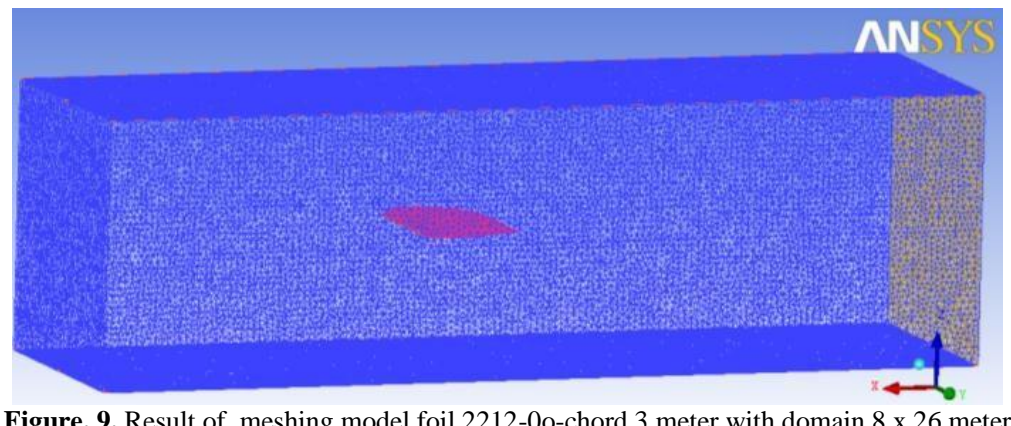

Figure. 9. Result of meshing model foil 2212-0o-chord 3 meter with domain 8 x 26 meter

From the graph and the table above, selected chord with dimensions $2.5 \mathrm{~m}$ have the highest efficiency with greatest force lift when compared to another foil with the same AOA.

So the foil for analysis HYSUCAT selected foil with a 4712 profile with a chord length of $2.5 \mathrm{~m}$.

Analysis resistance and power to foil 4712 Hysucat done using applications MAXSURF 11.12 and ANSYS 13.0.
Obtained differences between the two applications, seen from the table, resistance catamaran ship model using application ANSYS 13.0 has greater when compared with the results MAXSURF ver 11.12.

Differences resistance of ship models without or with foil using both applications results obtained following table.

TABLE 2.

RESISTANCE DAN EFFICIENCY MODEL CATAMARAN WITH FOIL 4712 USING ANSYS 13

\begin{tabular}{|c|c|c|c|c|}
\hline \multicolumn{3}{|c|}{ Start Resistance } & 44.1034 & $\mathrm{kN}$ \\
\hline No. & Foil & Angle & Resistance (N) & $\%$ \\
\hline 1 & \multirow{11}{*}{4712} & 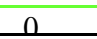 & 10585 & -140 \\
\hline 2 & & 4 & 12523 & -184 \\
\hline 3 & & 8 & 176.98 & -3.01 \\
\hline 4 & & 12 & 297.08 & -5.74 \\
\hline 5 & & 16 & 400.29 & -8.08 \\
\hline 6 & & 20 & 250.02 & -4.67 \\
\hline 7 & & 22 & 216.57 & -3.91 \\
\hline 8 & & 24 & 484.01 & -9.97 \\
\hline 9 & & 28 & 53058 & -1103 \\
\hline 10 & & 32 & 578.86 & -12.13 \\
\hline 11 & & 35 & 571.47 & -11.96 \\
\hline
\end{tabular}

TABLE 3.

RESISTANCE DAN EFFICIENCY MODEL CATAMARAN WITH FOIL 4712 USING MAXSURF 11.12

\begin{tabular}{|c|c|c|c|c|}
\hline \multicolumn{3}{|c|}{ Start Resistance } & 77.03 & $\mathrm{kN}$ \\
\hline No. & Foil & Angle & Resistance (N) & $\%$ \\
\hline 1 & \multirow{11}{*}{4712} & 0 & 7107 & مी \\
\hline 2 & & 4 & 7284 & 005 \\
\hline 3 & & 8 & 7221 & 0.06 \\
\hline 4 & & 12 & 74.00 & 0.04 \\
\hline 5 & & 16 & 73.88 & 0.04 \\
\hline 6 & & 20 & 70.39 & 0.09 \\
\hline 7 & & 22 & 69.19 & 0.10 \\
\hline 8 & & 24 & 73.13 & 0.05 \\
\hline 9 & & 28 & 7286 & 0.05 \\
\hline 10 & & 32 & 71.97 & 0.07 \\
\hline 11 & & 35 & 71.75 & 0.07 \\
\hline
\end{tabular}

Power 2x engine

: $2657.1 \mathrm{HP}$

- Resistance

- Speed

$78.1 \mathrm{kN}$

: $25 \mathrm{kts}$
From the initial condition without foil, model of catamaran that is made has the following characteristics:

Power $2 x$ engine

$$
\begin{aligned}
& : 2657.1 \mathrm{HP} \\
& : 78.1 \mathrm{kN} \\
& : 25 \mathrm{kts}
\end{aligned}
$$

- Speed

By using foil 4712 , chord $2.5 \mathrm{~m}$ on average have increased efficiency:

Power 2x engine :2398.49 HP (+8.19\%)

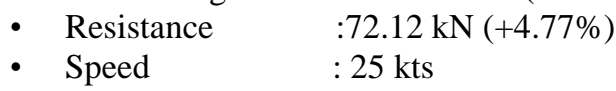

From the initial condition without foil, model of catamaran that is made has the following characteristics:
From the initial condition without foil, model of catamaran that is made has the following characteristics:

- $\quad$ Power 2x engine : $2383.5 \mathrm{HP}(+10 \%)$

- Resistance : $69.1 \mathrm{kN}(+10 \%)$

- Speed :25 kts 


\section{CONCLUSIONS}

After doing all the simulation models with a combination of foil and catamaran which has planned, and based on the results of the analysis and discussion it can be concluded as follows:

1) Foil the same chord length but with a thicker profile chamber will have a lift force greater at the same AOA, for the average of each profile foil around $16 \%$, with the largest $28 \%$ of displacement ship catamaran $25 \mathrm{~m}$.

2) AOA (angle of attack) at the same foil profile will affect to force of lift and drag on the foil, the greater AOA of the foil, it will have a lift and drag are getting bigger, with the average change for a lift of $140 \mathrm{kN}$, and drag $30 \mathrm{kN}$.

3) For relations between the AOA, lift and drag based on the chart, of each foil will have a point where the force lift reaches the greatest force, when once over that point, the foil will have a larger drag force and lift force will decreases in gradations, the condition is called a stall. Average foil has a stall at the point of AOA.

4) To increase force of lift and drag a foil, in addition to profiles foil, is also influenced by the foil chord length. Greater of the foil chord, make force of lift and drag is generated greater, due to the area of foil that is also bigger. This concept is carried out under the same AOA.

5) With using the foil, catamaran increased efficiency, the average efficiency of resistance increase $4.77 \%$, and increase power efficiency $8: 19 \%$.

6) Selection of profile foil, using foil with produce highest force lift (653 $167 \mathrm{kN})$ and has smallest drag force $(14035 \mathrm{kN})$.

\section{REFERENCES}

[1] Dwi Mardianto, Oky."Analisis Teknis dan Ekonomis Perancangan Kapal Cruise Wisata dengan Bentuk Hull Catamaran pada Rute Pelayaran Pelabuhan Manado - Taman Nasional Bunaken", Jurusan Teknik Perkapalan Fakultas Teknologi Kelautan, ITS Surabaya.

[2] Hoppe, K.G.W.'Recent Applications of Hydrofoil-SupportedCatamarans"

[3] Cocke, William."Shape Optimization of Hydrofoils".

[4] Kyaw, Htike Aung, Tin, Paing Hein Htet, Htet, Kaung Zaw.'Design of a Pleasure Craft with Catamaran Hull', Department of Naval Architecture and Ocean Engineering, Myanmar Maritime University. 